\title{
Forum
}

\section{The Relevance of Local-Scale Relationships to Habitat Management and Landscape Patterns}

\section{Pertinence des relations à l'échelle locale pour l'aménagement de l'habitat et le contexte du paysage}

\author{
$\underline{\text { Joseph J. Nocera }}^{1}, \underline{\text { Graham J. Forbes }}^{2}$, and $\underline{\text { G. Randy Milton }}^{3}$
}

Key Words: bird-habitat relationships; habitat management; latent variables; spatial scale.

In his response to our article (Nocera et al. 2007), Thogmartin (2007) invokes a quotation from Wiens et al. (1987) that implies our study was somehow invalid because we did not sample at multiple spatial scales. This needs to be put into context, as the subsequent paragraph in Wiens et al.'s paper supports our justification by stating "an analysis... that seeks a consistent relation to habitat features over the entire range will fail to demonstrate any but the strongest patterns." It was indeed the strongest patterns that we sought to identify, and we feel this renders our models conservative and therefore more reliable.

The goal of our study was "to determine which, if any, variables were consistently associated with indirect measures of fitness components." We reasoned, "if certain variables retain their importance across such a geographic distance as Nova Scotia to Iowa and Wisconsin...then we can make a case for model generality." We developed models from our study in Nova Scotia and observed, at the scale of 0.8 ha (the size of the plots surveyed), Bobolink (Dolichonyx oryzivorus) occupancy and abundance was correlated positively with heightdensity of grass in May. The relationship was supported when we confronted these models with independent data from Wisconsin and Iowa, which were collected at a very similar spatial scale. Savannah Sparrows (Passerculus sandwichensis) in
Nova Scotia were instead correlated negatively with grass height-density in May. The data from Iowa, but not those from Wisconsin, supported that relationship.

As Thogmartin (2007) suggests, these patterns may also be explained by relationships at other spatial scales. Although defining this dynamic was not our objective, had we included appropriate landscape variables in our analyses, we likely could have resolved this possibility more fully. This brings up an important point: latent (unmeasured) variables always have the potential for greater explanatory power than those measured. Unmeasured variables are a perpetually easy target for criticism because they are a common problem in ecological studies (Cade et al. 2005) and are a necessary by-product of attempting to study something complex. Spatial scale is just one of a huge number of potentially important variables that, in the interest of feasibility and/or parsimony, often remain unaddressed in studies of habitat use (see further suggestions in Frankham and Brook 2004, Bowler and Benton 2005). No ecological study can describe all variation in a process or pattern; this does not render the existing models invalid (we note that Thogmartin (2007) did not seek to directly refute our models).

As the hypothetical data plotted by Thogmartin (2007: Fig. 1) illustrate, landscape-scale processes

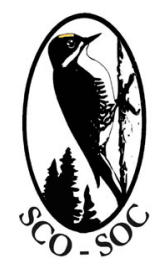

Sponsored by the Society of Canadian Ornithologists and Bird Studies Canada Parrainée par la Société des onithologistes du Canada et Études d'oiseaux Canada

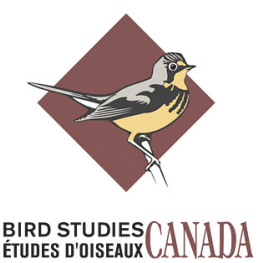
${ }^{1}$ Queen's University, ${ }^{2}$ University of New Brunswick, ${ }^{3}$ Nova Scotia
Department of Natural Resources 
may indeed constrain the habitat relationships we observed at a local scale. The study by Wiens et al. (1987) represents an extreme case of scaledependent observations; they demonstrated birdhabitat relationships changed with virtually every scale assessed. Although some relationships may only be relevant at a certain spatial scale, we encourage recollection that many studies have also demonstrated preferences that were consistent across scales (e.g., Walsh and Harris 1996, Wellnitz et al. 2001, Aunapuu and Oksanen 2003).

Inasmuch as landscape-level process may constrain local-scale patterns, local-scale processes may control landscape-scale relationships. This duality is hard to capture because there are three spatial scales of interest in any study (Dungan et al. 2002): the scale at which (i) the phenomenon of interest occurs, (ii) we measure, and (iii) we analyze. Ideally, we would seek to have the latter two items equal the first, or we can sample at multiple scales in attempt to capture the discrepancy.

It is important to remember that broader-scale models can sometimes describe less variation than more local-scale models (Erickson and West 2003, Betts et al. 2006, Koper and Schmiegelow 2006), although this is not universal. This needs to be considered when selecting scales at which to measure and analyze, as broader-scale models are more useful for regional planning, but local-scale models are more appropriate for dictating specialized management (Rouget 2003). Given this, we would add a fourth scale to the list by Dungan et al.: the scale at which we desire to manage habitat. Our models were not designed to assist with landscape planning or the arrangement of habitats, but rather to better manage existing hayfield habitat so as to provide advantage to breeding birds. In these cases, to maximize net benefit, it is pertinent to identify local-scale factors associated with habitat selection across a wide geographic area.

We feel that our models fit within this broad remit. The models we produced were confronted with independent data, and although they are limited to a fine spatial scale, they are now available for testing in other regions and at other scales.
Responses to this article can be read online at: http://www.ace-eco.org/vol3/iss1/art4/responses/

\section{LITERATURE CITED}

Aunapuu, M., and T. Oksanen. 2003. Habitat selection of coexisting competitors: a study of small mustelids in northern Norway. Evolutionary Ecology 17:371-392.

Betts, M. G., A. W. Diamond, G. J. Forbes, M.A. Villard, and J. S. Gunn. 2006. The importance of spatial autocorrelation, extent and resolution in predicting forest bird occurrence. Ecological Modelling 191:197-224.

Bowler, D. E., and T. G. Benton. 2005. Causes and consequences of animal dispersal strategies: relating individual behaviour to spatial dynamics. Biological Reviews 80:205-225.

Cade, B. S., B. R. Noon, and C. H. Flather. 2005. Quantile regression reveals hidden bias and uncertainty in habitat models. Ecology 86:786-800.

Dungan, J. L., J. N. Perry, M. R. T. Dale, P. Legendre, S. Citron-Pousty, M.-J. Fortin, A. Jakomulska, M. Miriti, and M. S. Rosenberg. 2002. A balanced view of scale in spatial statistical analysis. Ecography 25:626-640.

Erickson, J. L., and S. D. West. 2003. Associations of bats with local structure and landscape features of forested stands in western Oregon and Washington. Biological Conservation 109:95-102.

Frankham, R., and B. W. Brook. 2004. The importance of time scale in conservation biology and ecology. Annales Zoologici Fennici 41:459463.

Koper, N., and F. K. A. Schmiegelow. 2006. A multi-scaled analysis of avian response to habitat amount and fragmentation in the Canadian dry mixed-grass prairie. Landscape Ecology 21:10451059. 
Nocera, J. J., G. Forbes, and G. R. Milton. 2007. Habitat relationships of three grassland breeding bird species: broadscale comparisons and hayfield management implications. Avian Conservation and Ecology - Écologie et conservation des oiseaux 2 (1): 7. [online] URL: http://www.ace-eco.org/vol2/ iss1/art7/.

Rouget, M. 2003. Measuring conservation value at fine and broad scales: implications for a diverse and fragmented region, the Agulhas Plain. Biological Conservation 112:217-232.

Thogmartin, W. E. 2007. Effects at the landscape scale may constrain habitat relations at finer scales. Avian Conservation and Ecology - Écologie et conservation des oiseaux 2(2): 6. [online] URL: http://www.ace-eco.org/vol2/iss2/art6/.

Walsh, A. L., and S. Harris. 1996. Foraging habitat preferences of vespertilionid bats in Britain. Journal of Applied Ecology 33:508-518.

Wellnitz, T. A., N. L. Poff, G. Cosyleon, and B. Steury. 2001. Current velocity and spatial scale as determinants of the distribution and abundance of two rheophilic herbivorous insects. Landscape Ecology 16:111-120.

Wiens, J. A., J. T. Rotenberry, and B. van Horne. 1987. Habitat occupancy patterns of North American shrubsteppe birds: the effects of spatial scale. Oikos 48:132-147. 